\title{
Programa Mais Médicos e Atenção à Saúde em uma comunidade quilombola no Pará
}

\author{
The More Doctors Programme and the Health Care of a Pará State \\ quilombola community
}

\section{Lucélia Luiz PEREIRA* Leonor Maria Pacheco SANTOS**}

\begin{abstract}
Resumo: O presente artigo discute a atenção à saúde na comunidade quilombola de Jurussaca, no Pará, bem como analisa as repercussões da implantação do Programa Mais Médicos nesta comunidade. Realizou-se estudo de caso qualitativo, constituído por duas etapas - exploratória e de coleta de dados - na comunidade por meio de entrevistas semiestruturadas e grupo focal. Os atores-chaves da pesquisa foram usuários quilombolas, profissionais de saúde, gestores da Secretaria Municipal de Saúde e representante do Conselho Municipal de Saúde. Foram realizadas 30 entrevistas semiestruturadas, sendo 24 com usuários quilombolas adultos, e 1 grupo focal. Adotou-se a técnica de análise de conteúdo, com foco nas etapas empregadas por Bardin: pré-análise, exploração do material, tratamento e interpretação dos resultados. Os resultados apontaram que tanto a comunidade quilombola quanto os gestores apoiam e avaliam positivamente a implantação do Programa Mais Médicos. Os entrevistados ressaltaram que, após o Programa, houve aumento na qualidade do atendimento e ampliação de visitas domiciliares. Em relação à atenção à saúde, foi constatada a insuficiência dos serviços de saúde para garantir um atendimento equitativo e integral à saúde dos usuários quilombolas. Verificou-se uma fragilidade dos vínculos entre a equipe da Estratégia de Saúde na Família e a comunidade e uma inversão da lógica assistencial com maior procura pela atenção hospitalar. Os quilombolas afirmaram a existência de racismo e discriminação no atendimento. Assim, percebeu-se a necessidade de os serviços de saúde compreenderem as especificidades das demandas das comunidades quilombolas e suas características socioculturais e fomentarem ações de combate ao racismo institucional.
\end{abstract}

Palavras-chave: Saúde. Quilombola. Programa Mais Médicos. Rural. Norte.

\begin{abstract}
This article discusses health care in the Maroon (quilombola) community of Jurussaca, in Pará state, and analyses the repercussions of the More Doctors Programme in this community. A two-stage qualitative case study was carried out in the community, exploratory and data collection, by means of semi-structured interviews and focal group. The key actors of the research were Maroon health clientele, health professionals, municipal health department managers and representatives of the municipal health council. Thirty semistructured interviews were carried out, 24 with Maroon adults, and one focal group. The technique of content analysis was adopted, focusing on the steps employed by Bardin: pre-analysis, text exploration, treatment and interpretation of the results. The results showed that both the Maroon community and the managers evaluated the program positively and supported its implementation. The interviewees pointed out that after the programme there was an increase in the quality of care and in home-visits. Regarding health care, the results showed the inadequacy of healthcare services in guaranteeing an equitable and integrated service to the health of the Maroon clientele. Weaknesses were identified in the links between the Family Health Strat egy team and
\end{abstract}

\footnotetext{
* Doutora em Ciências da Saúde pela Universidade de Brasília (UnB). Docente no Departamento de Serviço Social da UnB. Campus Universitário Darcy Ri sbeiro | UnB | ICC Norte. CEP 7 0910-90o, Brasília (DF). Email: <lucelia@unb.br>. ORC ID: <https://orcid.org/oooo-ooo1-9722-143X>.

** Pós-doutora em Epidemiologia Materno-Infantil pela London School of Hygiene and Tropical Medicine. Docente no Departamento de Saúde Coletiva da UnB. Campus Universitário Darcy Ribeiro | UnB | Faculdade de Ciências da Saúde. CEP 70910-90o, Brasília (DF). E-mail: <leopac.unb@gmail.com>. ORC ID: $<$ https://orcid.org/oooo-0002-6739-6260>.
} 
the community and a reversal of the care logic, with greater demand for hospital care. The Maroons confirmed the existence of racism and discrimination in the healthcare services. Thus, healthcare services need to understand the specificities of the demands of the Maroon communities and their sociocultural characteristics and to encourage actions to counter institutional racism.

Keywords: Health. Maroon community. More Doctors Program. Rural. Northern region.

Submetido em: 12/1/2018. Revisto em: 10/5/2018. Aceito em: 2/7/2018.

\section{INTRODUÇÃO}

Na organização da atenção à saúde no Brasil, busca-se contemplar os vários aspectos do cuidado, como promoção, prevenção e tratamento, de forma a questionar o modelo hegemônico de atenção baseado somente na assistência às doenças. Para tal, em 1988, foi implantado o Sistema Único de Saúde (SUS), que defende um modelo de atenção integral a todos os cidadãos, considerando que, na Constituição Federal, a saúde é preconizada como um direito universal.

Estruturado a partir da atenção primária, secundária e terciária, o modelo de atenção à saúde brasileira busca priorizar estratégias de fortalecimento da promoção da saúde e prevenção de agravos. Desta forma, a Atenção Primária à Saúde (APS) é considerada a porta de entrada para o sistema de saúde, atuando na fase inicial do cuidado. A Conferência Internacional sobre Cuidados Primários à Saúde de 1978, em Alma-Ata, considerou a atenção primária fundamental, devendo ser garantida de forma universal às pessoas e famílias, por meio de ações contínuas e próximas ao local de moradia das pessoas (ORGANIZAÇÃO MUNDIAL DE SAÚDE, 1979).

Apesar da inovação conceitual na definição de atenção primária de Alma-Ata, quando se defenderam os princípios da integralidade, qualidade, equidade e participação social, é importante destacar que existem debates e concepções distintas sobre a atenção primária. Paim (2012) aponta uma imprecisão terminológica em relação à APS que facilita a convivência de várias concepções, desde um nível de atenção voltado a ser porta de entrada para os serviços de saúde até um serviço focalizado voltado principalmente para usuários em vulnerabilidade socioeconômica. O autor destaca ainda que há um movimento no sentido de fortalecer a APS, visando articular e desenvolver estratégias para reforçar a proposta defendida na Conferência de Alma-Ata a partir do diálogo não só com experiências de países da América Latina, mas também com movimentos organizados.

Embora haja marcos legais e normativos relacionados à equidade na atenção à saúde, os negros vivenciam condições de vida e saúde desfavoráveis e precárias e menor qualidade de atenção, além de terem perfil desvantajoso se comparado ao da população branca brasileira. Nesse sentido, o ensino e a pesquisa médica e das ciências sociais em saúde vêm analisando de que forma a variável raça influencia as situações de saúde e doença da população. A categorização racial nos estudos científicos permite dar visibilidade aos fatores não genéticos das enfermidades, ao abordar possíveis diferenças entre brancos e negros no que diz respeito à qualidade de vida, aos riscos de adquirir determinadas doenças e à resposta aos tratamentos, além do acesso aos serviços de saúde.

Argum., Vitória, v. 10, n. 2, p. 203-219, maio/ago. 2018. 
De acordo com a Política Nacional de Saúde Integral da População Negra (BRASIL, 2010), existe um consenso dos estudiosos brasileiros acerca de doenças e agravos à saúde dos negros. Portanto, a promoção da equidade no país depende também de uma abordagem específica destas doenças ou agravos.

No que diz respeito à saúde materno-infantil, alguns estudos mostram a disparidade das condições de saúde quando se considera raça, cor e etnia (BRASIL, 2009; GONÇALVES et al., 2009; INSTITUTO DE PESQUISA ECONÔMICA APLICADA, 2011; LEAL et al., 2005; LOPES, 2005; SANTOS et al., 2007). Tais estudos são fundamentais, pois evidenciam as desigualdades a partir de indicadores de acesso e cobertura aos serviços de pré-natal e parto, de maiores chances de mortalidade materna e infantil, de maior prevalência de insegurança alimentar e desnutrição etc. Grande parte destes estudos destacam os efeitos negativos do racismo no processo de saúde e doença, tendo em vista que tal realidade provoca maiores taxas de adoecimento e morte por causas evitáveis e quantidade maior de doenças associada à menor atenção à saúde (CUNHA, 2012; GUERRERO, 2010; TORALES, 2013).

Dados da Pesquisa Nacional de Demografia e Saúde da Criança e da Mulher 2006 também mostraram desvantagens da população negra. Apontaram um menor percentual de negras que realizaram seis consultas durante o pré-natal e que consultam no puerpério. $O$ nível de mortalidade infantil é $25 \%$ maior em crianças menores de 1 ano cujas mães se autodeclaram negras, o risco de morrer antes de completar 5 anos de vida é $29 \%$ mais elevado nas crianças negras se comparado com os filhos de mães brancas, e a incidência de insegurança alimentar moderada e grave também é mais elevada em domicílios cuja entrevistada era negra (BRASIL, 2009).

Desta forma, apesar de a legislação não distinguir grupos populacionais, as desigualdades sociais comprometem a saúde da população negra, demandando ações por parte do Estado para enfrentar a situação e garantir que os princípios da equidade, universalidade e integralidade sejam efetivados no SUS. Além disso, a despeito da constatação de tais desigualdades no estado de saúde bem como nos diferenciais de utilização dos serviços de saúde pelos negros, ainda são reduzidas as investigações voltadas a caracterizar e analisar as desigualdades raciais focando populações que apresentam maior vulnerabilidade social, como comunidades quilombolas. Essas comunidades são definidas legalmente como "[...] grupos étnicoraciais, segundo critérios de auto-atribuição, com trajetória histórica própria, dotados de relações territoriais específicas, com presunção de ancestralidade negra relacionada com a resistência à opressão histórica sofrida" (BRASIL, 2003, não paginado).

Em relação à atenção à saúde, estudo realizado na comunidade de Boqueirão, Bahia, aponta amplo desconhecimento da população dos fatores de risco para a hipertensão, como obesidade, sobrepeso, diabetes, baixa escolaridade e histórico familiar (AMORIM et al., 2013). Achado de investigação realizada por Oliveira et al. (2012) mostra que ocorre um grave problema de escassez de profissionais médicos, enfermeiros e agentes comunitários de saúde, além de uma alta rotatividade e transitoriedade destes profissionais. Volochko e Batista (2009) encontraram resultados semelhantes em estudo em comunidades quilombolas do Vale do Ribeira, em São Paulo, onde há alta rotatividade dos médicos contratados, além de dificuldades para realizar encaminhamentos e exames, bem como falta de medicamentos.

Argum., Vitória, v. 10, n. 2, p. 203-219, maio/ago. 2018. 
Além disso, as visitas dos agentes comunitários de saúde (ACS) às famílias quilombolas com usuários considerados prioritários geralmente não ocorrem pelo menos uma vez ao mês, conforme preconiza a Portaria n. 2.488 (BRASIL, 2011). Entre os fatores que impedem o cumprimento desta recomendação, destaca-se a distância entre os domicílios e a quantidade excessiva de famílias sob a responsabilidade dos ACS, além de indisponibilidade de transporte para percorrer as longas distâncias entre as casas (FREITAS et al., 2011).

Como estratégia para enfrentar o acesso insuficiente aos serviços de saúde e garantir a prevenção de doenças ou mesmo o tratamento, nos casos de adoecimento, alguns estudos relatam a utilização de plantas medicinais pelas comunidades quilombolas (AMORIM et al., 2013; FREITAS et al., 2009; VOLOCHKO; BATISTA, 2009). Ou seja, essas comunidades util izam o conhecimento ancestral, tradicional e cultural como forma de afirmar sua identidade, mas também para auxiliar a população em suas queixas de saúde, atendidas de forma insuficiente pelo Estado.

Desta forma, observa-se que as condições ambientais e socioeconômicas, associadas ao acesso limitado aos serviços de saúde de forma a usufruir de ações de educação em saúde, bem como medicamentos de fácil administração, contribuem para que a população negra, e mais especificamente as comunidades quilombolas, vivenciem situações de vulnerabilidade e inequidades em saúde.

Em nome disso, com o intuito de melhorar as condições de vida e saúde da população brasileira, incluso a população negra, nos últimos anos, algumas iniciativas governamentais vêm sendo implementadas pelo governo visando corrigir as disparidades existentes no campo da saúde. Destaca-se entre elas a implantação, em 2013, do Programa Mais Médicos, que tem como um dos seus públicos prioritários as comunidades quilombolas. O presente artigo discute a atenção à saúde na comunidade quilombola de Jurussaca, no Pará, bem como analisa as repercussões da implantação do Programa Mais Médicos nesta comunidade.

\section{Programa Mais Médicos}

Além do déficit de recursos humanos, a desigual distribuição dos profissionais de saúde dentro dos países e entre eles impacta as condições de vida e saúde das populações. Desta forma, buscando enfrentar o desafio mundial das disparidades em saúde, os países adotam diversas medidas, entre elas a migração de recursos humanos em saúde, reforçando o enfoque da saúde global a partir da cooperação entre países. Cuba se destaca nas experiências de cooperação médica bilateral, tornando-se referência na exportação de profissionais de saúde, geralmente por meio de cooperação técnica (MARIMÓN; MARTÍNEZ, 20o9; MONJE VARGAS, 2014).

Desde 1987 o Brasil mantém acordos de cooperação internacional com Cuba no campo da saúde (ANDRADE; LIMA, 2014). Tais cooperações são voltadas principalmente para a transferência de tecnologia, o desenvolvimento de novos medicamentos e vacinas e a contratação de profissionais para atuar no Brasil. Mais recentemente, implantou-se o Programa Mais Médicos (PMM), por meio de acordo firmado com o governo cubano, contando com a colaboração de médicos cubanos para atuar na atenção primária à saúde.

Argum., Vitória, v. 10, n. 2, p. 203-219, maio/ago. 2018. 
O PMM foi criado em 2013 a partir da Medida Provisória n. 621, de 8 de julho de 2013 (BRASIL, 2003c), e pela Lei n. 12.871 (BRASIL, 2013b). Tem como objetivo reduzir a escassez e má distribuição de médicos no país e criar novos cursos de medicina em áreas com carência destes profissionais. O provimento de médicos foi normatizado pela Portaria Interministerial n. 1.369, de 8 de julho de 2013, que institui o Projeto Mais Médicos para o Brasil (PMMB) como uma das estratégias integrantes do PMM (BRASIL, 2013a).

Portanto, semelhante a outros países que enfrentaram a ausência ou escassez de médicos em determinadas regiões, a partir do PMM, o Brasil permite a vinda de médicos estrangeiros, que desenvolvem suas atividades com licença provisória do Conselho Regional de Medicina. Tal licença permite que os médicos estrangeiros atuem somente durante o prazo estabelecido no contrato firmado e restringe o exercício das atividades às unidades básicas de saúde (UBS) da região onde forem alocados.

O PMM não só busca acabar com o persistente problema da escassez de médicos, principalmente nas áreas rurais e de difícil acesso, mas também possui componentes relacionados à formação médica e a melhorias na estrutura das UBS. Desta forma, o PMM tem o potencial de reduzir inequidades em saúde como também de fortalecer a rede de atenção primária à saúde.

De acordo com boletim do Observatório de Análise Política em Saúde (2017), até 2017 o PMM já havia sido implantado em 4.058 municípios, a partir da at uação de cerca de 18 mil médicos. Estudos apontam resultados positivos do PMM, tais como maior quantidade de médicos atuando na APS, aumento no número de consultas, ampliação de visitas domiciliares e redução de municípios com escassez deste profissional, como áreas rurais, quilombolas, abaixo da linha da pobreza, distantes dos grandes centros, e áreas indígenas (GIRARDI et al., 2016; PEREIRA; PACHECO, 2017; TRIBUNAL DE CONTAS DA UNIÃO, 2014).

Apesar dos avanços relevantes alcançados pelo PMM na organização da APS, é importante destacar os desafios da implementação da política de saúde brasileira na conjuntura atual de redução de recursos. No presente contexto, marcado por crise econômica, ajuste fiscal e contingenciamento de recursos orçamentários voltados ao desenvolvimento de políticas sociais, o SUS, mais especificamente a APS, encontra-se em risco. Ao analisar as novas regras fiscais sobre gastos de recursos federais para a saúde, vigentes a partir de 2016, os autores Vieira e Benevides (2016) apontam que haverá redução de despesa federal com saúde. Os autores destacam que, "[...] em comparações internacionais, o gasto público com saúde do Brasil se situa abaixo do gasto de países que possuem sistema universal de saúde, e mesmo abaixo do gasto de países da América Latina nos quais a saúde não constitui um dever do Estado" (VIEIRA; BENEVIDES, 2016, p. 9).

Portanto, os recursos voltados à implementação do SUS, que já eram considerados insuficientes, serão reduzidos após a aprovação da Emenda Constitucional n. 95, de 2016. Esta emenda instituiu um novo regime fiscal, limitando por 20 anos o crescimento das despesas primárias à taxa de inflação (BARSIL, 2016). Em nome disso, a implementação da política de saúde está sendo afetada, o que certamente acarretará a redução do acesso da população à atenção à saúde.

Argum., Vitória, v. 10, n. 2, p. 203-219, maio/ago. 2018. 


\section{Percurso Metodológico}

O estudo foi realizado na comunidade quilombola de Jurussaca, mesorregião do nordeste do Pará, localizada a $11 \mathrm{~km}$ da sede do município e a 9 quilômetros da UBS mais próxima. A população da comunidade oscila entre 500 e 600 pessoas, com aproximadamente 90 famílias. A comunidade foi titulada em 2002 pelo Instituto de Terras do Pará (Iterpa). A principal atividade econômica desenvolvida é a agricultura de subsistência, a partir do plantio da mandioca e do feijão.

Foi realizado um estudo de caso qualitativo, constituído por duas etapas de coleta dos dados, com as técnicas de entrevista semiestruturada e grupo focal. Os participantes da pesquisa foram constituídos por quatro grupos: usuários moradores da comunidade quilombola, profissionais de saúde da equipe da Estratégia Saúde da Família (ESF) de referência da comunidade, gestores da Secretaria Municipal de Saúde e representante do Conselho Municipal de Saúde. A inclusão destes atores-chaves na pesquisa justifica-se pelo papel estratégico que cada grupo ocupa na comunidade bem como pelo conhecimento e experiência com o PMM, seja como usuários, seja no exercício do controle social ou na gestão da política, o que os capacita a analisar as repercussões do PMM na comunidade. Em relação aos gestores, foram convidados a participar aqueles envolvidos diretamente na coordenação da atenção básica. Já os profissionais e usuários quilombolas foram contatados na UBS onde o médico do PMM estava alocado.

Foram realizadas 30 entrevistas semiestruturadas, 1 grupo focal e anotações no diário de campo a partir do cotidiano de atendimento à comunidade pelos serviços de saúde, como consultas, visitas domiciliares e sala de acolhimento. Para a coleta de dados junto aos gestores e ao representante do conselho, foram realizadas entrevistas semiestruturadas. No caso dos usuários, além das entrevistas, foi conduzido um grupo focal com 12 usuários atendidos pelo médico do PMM, buscando apreender percepções sobre o programa bem como suas repercussões na atenção à saúde da comunidade.

O projeto de pesquisa matriz, do qual esta investigação faz parte, foi submetido e aprovado por um Comitê de Ética em Pesquisa. Além disso, antes de iniciar as entrevistas e grupos focais, foram apresentados os objetivos e a justificativa da investigação e disponibilizado o Termo de Consentimento Livre e Esclarecido (TCLE), que foi lido e posteriormente assinado pelos interessados em participar da pesquisa.

Para o exame dos dados, adotou-se a técnica de análise de conteúdo, com foco nas etapas empregadas por Bardin (2010): pré-análise, exploração do material, tratamento e interpretação dos resultados. Na execução das etapas de análise, utilizou-se como ferramenta de apoio o software Atlas-ti, procedendo assim à sistematização e categorização das informações e à análise à luz da literatura, com foco nas questões pertinentes ao estudo.

Desta forma, para a sistematização da coleta de dados, o conteúdo das entrevistas e do grupo focal foi transportado para o software Atlas-ti, com base em duas categorias, subdivididas em subcategorias: 1) atenção à saúde na comunidade: atividades de promoção e educação em saúde, atendimento do ACS, percepção sobre disponibilidade dos serviços de saúde no município e atendimento na UBS; e 2) mudanças/alterações na atenção à saúde após a im-

Argum., Vitória, v. 10, n. 2, p. 203-219, maio/ago. 2018. 
plantação do PMM: percepção sobre o PMM, planejamento do trabalho na UBS, percepção sobre atuação/atendimento do médico do PMM, mudanças observadas com a chegada do médico na unidade de saúde.

\section{"Não vou beber chá de receita": atenção à saúde na Comunidade Quilombola}

A comunidade quilombola configura-se como uma das subáreas sob a responsabilidade da ESF 1, que é composta por médico do PMM, enfermeira, odontóloga, duas técnicas de enfermagem, auxiliar de enfermagem, sete ACS, auxiliar de serviços gerais, duas agentes administrativas e técnica de saúde bucal. A ESF atende dez subáreas, todas rurais, e fica a cerca de 15 quilômetros da sede do município.

De acordo com usuários, profissionais e gestores, as principais enfermidades que acometem a comunidade são: hipertensão, diabetes, diarreia, problemas na coluna, anemia e resfriado. Em menor número, foram relatadas doenças como câncer, anemia falciforme e depressão. A atenção à saúde da comunidade ocorre por meio de: 1) atuação do técnico de enfermagem; 2) realização do comando médico na comunidade; 3) participação dos usuários nas ações e atividades ofertadas pela UBS 1;4) aquisição de planos funerários; e 5) utilização de medicina alternativa.

A comunidade está sem ACS há mais de quatro anos. Buscando sanar temporariamente essa ausência, e após mobilização e reivindicação dos moradores, a Secretaria de Saúde designou um técnico de enfermagem para desempenhar as atribuições do ACS.

\footnotetext{
A secretaria colocou um menino, um técnico de enfermagem para trabalhar na comunidade, mediante a reivindicação da comunidade, porque tinha muito hipertenso, diabéticos e tal, pra tá dando esse suporte até a inauguração da UBS. Eu vejo isso como uma conquista, porque eu entendo que a comunidade entendeu que é um direito dela, né, e a gestão não disse não, realmente atendeu, né, que foi uma reivindicação dos próprios moradores (representante do Conselho de Saúde).
}

Assim como o representante do conselho, os moradores da comunidade avaliaram como positiva a atuação do técnico de enfermagem, no entanto, alguns ressaltaram que,

[...] ajudou muito pra gente esse menino andar por aqui, vim visitar a gente, fazer o curativo nos pés dos idosos. Agora, só tem um e a comunidade é grande, é uma lonjura a distância das casas, e aí fica difícil ele ver todo mundo que precisa. Dizem que ele tá só para conversar com pessoas com pressão descontrolada e aqueles diabéticos (usuário, 78 anos).

Além da atuação do técnico de enfermagem, a equipe da UBS 1 realiza o Comando Médico, ação que ocorre mensalmente ou a cada 45 dias, dependendo da disponibilidade dos profissionais. Consiste no deslocamento da equipe da UBS até a comunidade, durante uma manhã, para a realização de atendimento médico, odontológico e de enfermagem.

Pergunta: Normalmente os moradores vêm no Comando pra quê? Para consultar?

É pra consultar também, porque é assim, tem avaliação do Bolsa Família que a gente faz, que aqui não tem ACS, a gente que faz. Aí a gente veio mês passado, pesamos tudinho, agora só faltou um pouco pra pesar. Mas todo mês a doutora vem consultar,

Argum., Vitória, v. 10, n. 2, p. 203-219, maio/ago. 2018. 
a enfermeira vem pra consultar também, orientar tudinho. Aí a gente faz vacina também, entrega remédio quando tem, a gente faz um monte de coisas (profissional de saúde).

Com o Comando se resolve em parte, em parte, mas não pode resolver tudo. A equipe faz uma vez por mês, faz o atendimento lá na comunidade. Eu tenho planejado visita lá, visita normal de acompanhamento. Lá ainda não tem ACS, tem o técnico de enfermagem, que faz essa função de todos (médica da UBS 1).

Apesar de concordarem com os profissionais sobre a importância do atendimento itinerante, os moradores destacaram as limitações da ação, uma vez que não há uma periodicidade estabelecida para sua ocorrência e também, muitas vezes, o Comando acontece com ausência de profissionais, principalmente da odontologia. Além disso, ressaltam que nem sempre a equipe leva medicamentos e vacinas, sendo necessário o deslocamento dos usuários para a UBS após as consultas.

A outra forma de acesso dos quilombolas ao atendimento à saúde ocorre por meio da participação nas ações e atividades realizadas na UBS. No entanto, os usuários quilombolas destacam algumas barreiras para acesso ao atendimento, principalmente o deslocamento, tendo em vista a distância entre a comunidade e a UBS.

Em relação à UBS, há poucos relatos de realização de atividades coletivas. Na maioria das vezes, os usuários vão para consultas individuais com a médica, enfermeira ou odontóloga. Suas falas indicam que não há vínculo com a equipe e que é reduzida a participação nas at ividades ofertadas pela UBS. Além disso, relatam a preferência pelo hospital, afirmando que só procuram os serviços de saúde quando "não tem mais jeito". Buscam uma atenção relacionada à consulta individualizada e têm uma lógica de resolutividade vinculada a medicação e exames: "[...] as dificuldades maior é sobre o remédio do posto, porque nunca tem, então o que eu vou fazer lá? Não vou beber chá de receita, a gente chega lá quase morrendo e não tem remédio" (usuária, 46 anos).

No entanto, há nuances nas falas dos usuários. Se, por um lado, há uma valorização e procura maior por serviços hospitalares, por outro lado, reivindica-se uma UBS na comunidade quilombola e a ampliação de visitas domiciliares, demonstrando um desejo pela oferta adequada de serviços de prevenção e educação em saúde, buscando uma substituição ao modelo tradicional de assistência, focado na cura de doenças (TEIXEIRA; SOLLA, 2006).

Outra questão apontada pelos usuários é a existência de preconceito no atendimento. Eles afirmam que preferem ir para o hospital do que para a UBS, porque há um tratamento diferenciado na UBS. Para eles, os quilombolas são tratados de forma diferente:

Eu acho que existe um certo preconceito, preconceito sim, tem alguma coisa estranha que até agora eu não entendi direito, mas a gente é tratado diferente (usuário, 68 anos).

Lá em [UBS 1], às vezes eles ficam colocando os de lá na frente e a gente fica por último e muita das vezes a gente chegou primeiro. Eu me sinto, eu prefiro não ir. Quando não, eu pego o ônibus e vou bater lá na cidade (usuária, 43 anos).

Argum., Vitória, v. 10, n. 2, p. 203-219, maio/ago. 2018. 
O pessoal de [UBS 1] atende o pessoal daqui mal, acho que é porque a gente é da raça negra, somos pretos, né? (usuária, 66 anos).

Apesar de um dos profissionais da UBS afirmar que realmente os usuários quilombolas já se queixaram sobre o atendimento, gestores e representante do conselho desconhecem tal queixa: "[...] é, eles alegam, assim, que não gostavam daqui do posto, o atendimento das pessoas que trabalham não é legal com eles. Eles achavam que eram discriminados, entendeu?" (profissional de saúde).

O racismo institucional é também chamado de discriminação indireta, tendo em vista que se apresenta velado em muitas situações, ou seja, os atos não são declarados explicitamente, por isso, não são facilmente detectados ou comprovados. De acordo com Jaccoud (2008), ele atua no nível das organizações, nos procedimentos cotidianos, promovendo o acesso diferenciado a serviços e bens.

Desta forma, apesar das possibilidades de acesso apresentadas, os usuários quilombolas relatam dificuldades de acesso aos serviços de saúde do SUS. Uma alternativa utilizada por eles é a aquisição de planos funerários em que os associados e seus dependentes pagam uma taxa mensal ou uma anuidade de valor baixo, se comparado aos serviços de saúde suplementar, e têm direito a serviços que extrapolam a natureza do negócio. Assim, as funerárias oferecem para os associados desconto no valor de consultas médicas, tratamento odontológico, exames laboratoriais e transporte de ambulância para pessoas com dificuldade de locomoção.

É tipo um seguro que a gente paga, né? Aí fecha o negócio com uma funerária e dá direito às coisas, pode fazer exames, consultas, tem transporte do doente, dentadura você dá metade e eles dá metade, aí a gente tem desconto. E tem também, Deus me livre e guarde, a gente morre, eles dão o caixão, a urna (usuária, 62 anos).

O chamado cartão de desconto ofertado pelos planos funerários não tem uma regulamentação da Agência Nacional de Saúde (SANTOS et al., 2008). Esses benefícios em vida dados pelas funerárias, como assistência médica, clínicas e laboratórios, são comparados aos serviços de saúde suplementar; no entanto, a falta de regulamentação e fiscalização dos órgãos de saúde pode acarretar serviços de má qualidade, trazendo prejuízos aos usuários.

A utilização de serviços privados, seja na forma de compra de planos funerários, seja na de compra de medicamentos e realização de exames particulares pela comunidade quilombola, demonstra que, mesmo sem condições financeiras, as lacunas na atenção à saúde pública têm levado à ampliação da procura pela rede privada de atenção à saúde (BOING et al., 2014).

Outra alternativa, tradicional e de cunho cultural, adotada pela comunidade para sanar as dificuldades de acesso à rede de serviços de saúde é a utilização da medicina alternativa a partir do preparo de chás, garrafadas e benzeção. Tal prática demonstra o recurso a saberes ancestrais que contribuem localmente para a proteção e promoção da saúde dos moradores e evidencia o pluralismo terapêutico existente nestas comunidades (ABREU, 2012). A prática da medicina popular é relatada por diversos estudos relacionados à atenção à saúde em comunidades quilombolas (AMORIM et al., 2013; FREITAS et al., 2009; VOLOCHKO; BATISTA, 2009). A comunidade também relata o costume de se automedicar, não só com remé-

Argum., Vitória, v. 10, n. 2, p. 203-219, maio/ago. 2018. 
dios caseiros, como também alopáticos. "A gente tinha muita rezadeira aqui com nós, aí foi morrendo tudinho. Agora ainda tem gente que reza de quebranto, de mau olhado, e agora a gente tem só um pajé, que faz outras rezas" (usuária, 58 anos).

Percebe-se que a atenção à saúde da comunidade ocorre tanto pela participação nos serviços de saúde ofertados quanto pelo uso da medicina alternativa. Uma questão que chama a atenção é a necessidade de fortalecimento do modelo de atenção à saúde voltado à promoção da saúde. Os vínculos dos usuários quilombolas com a ESF de referência estão fragilizados, já que se busca como primeira instância de tratamento os conhecimentos advindos da sabedoria popular e medicina alternativa, depois a automedicação e, somente após este percurso, os serviços da UBS ou do hospital na cidade.

\section{"Santo de casa não faz milagre": percepção dos atores sociais sobre repercussões do Programa Mais Médicos na atenção à saúde da Comunidade Quilombola}

Desde a implantação do PMM, em 2013, três médicos cubanos atuaram na UBS 1. Apesar da tendência de procurar serviços de saúde na cidade e das queixas em relação ao atendimento na UBS de referência, muitos moradores da comunidade frequentam a UBS e foram atendidos pelo médico do PMM, possibilitando assim uma análise sobre a atenção à saúde a partir do PMM com base na percepção tanto dos usuários quilombolas como de outros atores sociais envolvidos no estudo.

A questão mais recorrente nas falas dos entrevistados diz respeito à qualidade das consultas médicas com a chegada dos médicos do PMM. Tanto usuários quanto profissi onais tendem a realizar uma comparação entre médicos cubanos e médicos brasileiros que participaram da equipe da ESF anteriormente.

Eu acho que foi uma boa ideia do governo trazer esses médicos, porque eles faz o trabalho direito, eles são bons profissionais, e às vezes santo de casa não faz milagre, às vezes os brasileiros não tão agindo direito, né, porque é difícil conseguir um brasileiro para ficar um tempinho maior aqui na área, sempre vai embora logo (usuária, 43 anos).

O atendimento é avaliado como satisfatório pelos entrevistados, que relatam que a consulta é muito boa porque recebem atenção e explicações sobre as enfermidades e têm espaço para verbalizar o que sentem. Resultados semelhantes em relação à avaliação positiva e satisfação dos usuários foram encontrados em outros estudos sobre o PMM (BRITO, 2014; ORGANIZAÇÃO PAN-AMERICANA DA SAÚDE, 2015).

Ainda em relação à percepção sobre o PMM, os gestores do município destacaram os ganhos sociais e de atenção à saúde alcançados com a atuação dos médicos do programa. Avaliam que houve aumento do número de consultas e, consequentemente, de solicitação de exames e medicamentos. Este resultado converge com outros estudos sobre o PMM, mostrando as alterações nos serviços de saúde de atenção primária após a implantação do programa (MOLINA et al., 2014; ORGANIZAÇÃO PAN-AMERICANA DA SAÚDE, 2015; TRIBUNAL DE CONTA DA UNIÃO, 2014). Destacam a humanização dos atendimentos e o fortalecimento da atenção básica, uma vez que os médicos cubanos realizam atividades de educação em saúde.

Argum., Vitória, v. 10, n. 2, p. 203-219, maio/ago. 2018. 
Para o médico cubano que atua na área quilombola, a experiência de atuar no Brasil tem sido muito rica e proveitosa. Ele ressalta que tal oportunidade permite o conhecimento do SUS e também da realidade de saúde de municípios pequenos. Destaca que a atuação na comunidade quilombola é um desafio, principalmente porque a área tem muitos moradores com doenças crônicas que não eram acompanhados de forma sistemática pela UBS.

É um desafio que nós enfrentamos porque, no acompanhamento médico, eu pergunto: 'não está tomando o remédio por quê? E os médicos não falaram para você que tem uma doença crônica, que então necessita tomar remédio a vida toda?' Eles não sabem, então toma remédio trinta dias, enquanto dura, e não toma mais. Então tem muitos hipertensos, diabéticos que não acompanham a enfermidade, que não sabe quase nada sobre estas doenças, então necessita de educação em saúde, palestras, e mudar os hábitos (médico da UBS 1 ).

Essa reflexão trazida pelo médico é uma realidade na comunida de quilombola. Vários moradores entrevistados relataram a não assiduidade na utilização dos medicamentos para controle das doenças crônicas, e alguns destacaram que tiveram conhecimento da necessidade de utilização contínua somente após consultas com o médico e enfermeiro.

De acordo com os profissionais entrevistados, as ações de educação em saúde ocorrem tanto na UBS, por meio de palestras, quanto no âmbito individual no momento dos atendimentos realizados pela equipe. Alguns dos profissionais entrevistados destacaram que as ações de educação em saúde foram intensificadas com a chegada do PMM, uma vez que o médico tem uma postura de maior envolvimento com a realização de ações coletivas e também desenvolve ações nas visitas domiciliares. $\mathrm{O}$ médico cita que várias enfermidades estão relacionadas às condições de higiene e aos hábitos alimentares dos usuários.

Eu sempre falo para eles, o remédio é um bem, mas só resolve uns $25 \%$, e o resto, os $75 \%$, tem que ser a dieta, é o que a senhora come, principalmente nos casos de diabetes. Mas aí é difícil, tem que conversar muito com eles para tentar ver se comem menos gorduras, sal, farinha, que é o que consomem muito nessa região (médico da UBS 1).

Helman (2003) chama atenção, no entanto, para a necessidade da não culpabilização do usuário pela enfermidade, já que a má saúde de uma população está associada à cultura, mas também à situação econômica e social. Desta forma, os problemas de saúde estão relacionados à situação alimentar, à higiene e ao estilo de vida, devendo ser compreendidos em sua totalidade, inclusive considerando as dificuldades de nutrição, habitação, saneamento e destinação de lixo, que podem estar fortemente relacionadas à situação de saúde da coletividade.

O médico ressalta que, além da hipertensão e diabetes, os moradores enfrentam problemas de saúde relacionados à obesidade e diarreia. À condição social desfavorável das famílias está aliada a questão da falta de informação em saúde, o que acaba sendo um fator de vulnerabilidade para os moradores. Por isso, o médico considera a visita domiciliar uma estratégia importante para compreender a realidade dos moradores, bem como buscar elementos que os auxiliem na promoção da saúde a partir de suas práticas e saberes.

Argum., Vitória, v. 10, n. 2, p. 203-219, maio/ago. 2018. 
Eu acho interessante porque a médica, quando vai na casa, vai para fazer a visita, ela se preocupa muito, ela quer saber de tudo, do lixo, da fossa, do banheiro, da água... Pergunta também da comida que eles comem, quer saber muita coisa, e é bom, né, porque aí ela conversa com a família, e às vezes eles até muda um pouquinho os costumes que às vezes faz mal, e melhora a saúde (profissional de saúde).

A visita domiciliar é um importante instrumento de comunicação, podendo facilitar o processo de vínculo entre usuários e equipe de saúde. Além disso, permite uma aproximação com a realidade das famílias, bem como a detecção de situações de vulnerabilidade e inequidades, garantindo, assim uma maior integralidade do cuidado (BARROS; CHIESA, 2007; FREITAS et al., 2012). Apesar da importância de sua realização, moradores e profissionais ressaltam que antes do PMM as visitas domiciliares, principalmente de médicos à comunidade, eram praticamente inexistentes, o que fragilizava muito a atenção à saúde na comunidade. "Para mim, a chegada do médico foi excelente, até porque, antes do Mais Médicos, o pessoal tinha uma dificuldade enorme de fazer visita, praticamente não existia visita domiciliar" (profissional de saúde).

Outra alteração importante desde a implementação do PMM é a busca pelo fortalecimento de um modelo de atenção que priorize as ações de promoção da saúde.

[...] É caro, mas os pacientes adoram tomografia e ressonância e nas consultas eles sempre pedem. Eu explico, tento fazer um processo de educação em saúde, porque nem sempre precisa de exames especializados, na consulta já é possível chegar a um diagnóstico, ou então com exames mais simples (médico da UBS1).

[...] No programa [Mais Médicos], a gente tem um médico que trabalha atenção básica mesmo. Os exames que eles solicitam realmente são aqueles que são mesmo necessários, enquanto que os outros médicos não, as pessoas têm facilidade, é só falar: "Dr., passa uma tomografia pra mim", aí uns já passam. Agora, os cubanos, não, eles verificam a necessidade (gestor da Secretaria de Saúde).

Tanto gestores como profissionais entrevistados destacaram que o médico recorre a exames somente quando avalia sua necessidade para completar o diagnóstico. $\mathrm{O}$ médico observa a expectativa comum dos usuários de que na consulta sejam solicitados muitos exames, no entanto, ressalta a importância de que, na atuação da ESF, sejam priorizadas ações de educação em saúde.

A tentativa de fortalecimento do modelo de atenção voltado à prevenção é fundamental, tendo em vista que, apesar de o SUS preconizar uma lógica de atenção voltada à promoção da saúde, os usuários tendem a procurar uma atenção hospitalocêntrica e medicalizada, uma vez que encontram falhas na implementação da atenção básica da UBS. A Política Nacional da Atenção Básica define que ações em saúde sejam voltadas para o território, de forma continuada e integral (BRASIL, 2011). Além disso, a atenção deve ter como base o vínculo entre usuários e equipe de saúde, garantindo a continuidade e longitudinalidade do cuidado (GIOVANELLA; MENDONÇA, 2012).

Além da ampliação de visitas domiciliares e de ações de educação em saúde, outra mudança percebida em relação à atuação do PMM foi o maior envolvimento do profissional médico 
no planejamento das ações não só na UBS, mas também em fóruns de discussão da política de saúde.

Apesar das diversas mudanças relatadas pelos atores sociais em relação à UBS após atuação do PMM, a experiência de atenção à saúde na comunidade quilombola pode ser considerada um exemplo de que uma atenção à saúde mais satisfatória depende não só do provimento de médico, mas também de mudanças na organização dos serviços e de condições adequadas de infraestrutura para a UBS e a rede de serviços ofertados.

\section{CONSIDERAÇÕES FINAIS}

Os dados da pesquisa apontaram que a comunidade quilombola apoia a iniciativa governamental de implantação do PMM e faz uma avaliação positiva sobre a atuação médica na UBS, ressaltando a qualidade no atendimento e o aumento de visitas domiciliares. Assim como os usuários, os gestores veem como positiva a adesão do município ao programa.

Em relação à atenção à saúde, de modo geral, os resultados mostraram a insuficiência dos serviços de saúde para garantir um atendimento integral à comunidade quilombola, uma vez que a comunidade não tem ACS, a UBS é distante e os comandos médicos são realizados numa temporalidade espaçada. Tal lacuna na atenção à saúde reforça a fragilidade dos vínculos entre equipe da ESF e usuários e contribui para inverter a lógica do modelo de atenção, tendo em vista a procura da medicina curativa/hospitalar. Além disso, a oferta insuficiente de recursos pelo SUS reforça uma lógica privada de assistência, pois os usuários passam a buscar os serviços privados para realizar exames e adquirir medicamentos, muitas vezes, por meio da adesão e pagamento de planos funerários, que oferecem outros benefícios.

Portanto, para a garantia de maior acesso da comunidade quilombola aos serviços de saúde é importante melhorar o atendimento na UBS, a infraestrutura e o serviços de contrarreferência. Fundamentalmente, é preciso compreender as especificidades das demandas das comunidades quilombolas e suas características socioculturais e de saúde para contribuir na redução das inequidades em saúde, ainda presentes na realidade estudada.

\section{REFERÊNCIAS}

ABREU, W. C. Saúde, doença e diversidade cultural: medicina e saúde. Lisboa: Instituto Piaget, 2012.

AMORIM, M. M. et al. Avaliação das condições habitacionais e de saúde da comunidade quilombola Boqueirão, Bahia. Bioscience Journal, v. 29, n. 4, p. 1049-1057, 2013.

ANDRADE, A. L.; LIMA, R. S. F. Brasil-Cuba e as cooperações no campo da saúde: Acordo para o Desenvolvimento de Medicamentos contra o Câncer e Doenças Autoimunes. Florianópolis: Observatório de Negociações Internacionais da América Latina, 2014.

BARDIN, L. Análise de conteúdo. Lisboa: Edições 70, 2010. 
BARROS, D. G.; CHIESA, A.M. Autonomia e necessidades de saúde na sistematização da assistência de Enfermagem no olhar da saúde coletiva. Revista da Escola de Enfermagem da USP, São Paulo, v. 41, n. esp., p. 793-798, 2007.

BOING, A. C. et al. Influência dos gastos em saúde no empobrecimento de domicílios no Brasil. Revista de Saúde Pública, Rio de Janeiro, v. 48, n. 5, p. 797-807, 2014.

BRASIL. Presidência da República. Decreto no 4.887, de 20 de novembro de 2003. Regulamenta o procedimento para identificação, reconhecimento, delimitação, demarcação e titulação das terras ocupadas por remanescentes das comunidades dos quilombos de que trata o art. 68 do Ato das Disposições Constitucionais Transitórias. Diário Oficial [da] República Federativa do Brasil, Brasília [DF], 21 nov. 2003.

BRASIL. Ministério da Saúde. Centro Brasileiro de Análise e Planejamento. Pesquisa Nacional de Demografia e Saúde da Criança e da Mulher - PNDS 20o6: dimensões do processo reprodutivo e da saúde da criança. Brasília [DF], 2009.

BRASIL. Ministério da Saúde. Secretaria de Gestão Estratégica e Participativa. Política Nacional de Saúde Integral da População Negra: uma política para o SUS. Brasília, 2010.

BRASIL. Presidência da República. Portaria n. 2.488, de 21 de outubro de 2011. Aprova a Política Nacional de Atenção Básica, estabelecendo a revisão de diretrizes e normas para a organização da Atenção Básica, para a Estratégia Saúde da Família (ESF) e o Programa de Agentes Comunitários de Saúde (PACS). Diário Oficial [da] República Federativa do Brasil Brasília (DF), 2011.

BRASIL. Presidência da República. Portaria Interministerial n. 1.369, de 8 de julho de 2013. Dispõe sobre a implementação do "Projeto Mais Médicos para o Brasil". Ministério da Saúde. Diário Oficial [da] República Federativa do Brasil. Brasília (DF), $2013 a$.

BRASIL. Presidência da República. Lei n. 12.871, de 22 de outubro de 2013. Institui o Programa Mais Médicos, altera as Leis n. 8.745, de 9 de dezembro de 1993, e n. 6.932, de 7 de julho de 1981, e dá outras providências. Diário Oficial [da] República Federativa do Brasil, Brasília (DF), 23 out. 2013 b. Seção 01, p. 42.

BRASIL. Presidência da República. Medida Provisória n. 621, de 8 de julho de 2013. Institui o "Programa Mais Médicos" e dá outras providências. Diário Oficial [da] República Federativa do Brasil, Brasília (DF), 9 jul. 2013c. Seção o1.

BRASIL. Constituição (1988). Emenda Constitucional n. 95, de 2016. Altera o Ato das Disposições Constitucionais Transitórias, para instituir o Novo Regime Fiscal, e dá outras providências. Brasília (DF), 2016.

BRITO, L. M. Programa Mais Médicos: satisfação dos usuários das Unidades Básicas de Saúde de Ceilândia (DF) quanto ao atendimento médico. 2014. Monografia (Graduação em Saúde Coletiva)-Universidade de Brasília, Brasília (DF), 2014. 
CUNHA, E. M. G. P. Recorte étnico-racial: caminhos trilhados e novos desafios. In: BATISTA, L. E. et al. (Orgs.). Saúde da população negra. 2. ed. Brasília: Associação Brasileira de Pesquisadores Negros, 2012.

FREITAS, D. A. et al. Saúde e comunidades quilombolas: uma revisão da literatura. Revista CEFAC, São Paulo, v. 13, n. 5, p. 937-943, 2011.

FREITAS, D. B. et al. A relação do lazer com a saúde nas comunidades quilombolas de Santarém. Revista Brasileira de Ciências do Esporte, Brasília (DF), v. 30, n. 2, p. 89-105, 2009.

FREITAS, L.N.F. et al. Desafios da atenção básica frente às iniquidades em saúde. Revista Opinião Filosófica, Porto Alegre, v. 3, n. 1, p. 50-59, 2012.

GIOVANELLA, L.; MENDONÇA, M. H. M. Atenção Brasil. Atenção Primária à Saúde. In: GIOVANELLA, L. et al. (Orgs.). Políticas e sistemas de saúde no Brasil. 2. ed. rev. ampl. Rio de Janeiro: Fiocruz, 2012.

GIRARDI, S. N. et al. Impacto do Programa Mais Médicos na redução da escassez de médicos em Atenção Primária à Saúde. Ciência \& Saúde Coletiva, Rio de Janeiro, v. 21, n. 9, p. 2675-2684, set. 2016.

GONÇALVES, C. V. et al. Qualidade e equidade na assistência à gestante: um estudo de base populacional no Sul do Brasil. Cadernos de Saúde Pública, Rio de Janeiro, v. 25, n. 11, p. 2507-2516, 2009 .

GUERRERO, A. F. H. Situação nutricional de populações remanescentes de Quilombos do Município de Santarém, Pará - Brasil. 2010. Tese (Doutorado em Saúde Pública)Programa de Pós-Graduação da Escola Nacional de Saúde Pública Sérgio Arouca, Rio de Janeiro, 2010.

HELMAN, C. G. Cultura, saúde e doença. 4. ed. Porto Alegre: Artmed, 2003.

INSTITUTO DE PESQUISA ECONÔMICA APLICADA. Retrato das desigualdades de gênero e raça. 4. ed. Brasília (DF), 2011.

JACCOUD, L. O combate ao racismo e à desigualdade: o desafio das políticas públicas de promoção da igualdade racial. In: THEODORO, M. (Org.). As políticas públicas e a desigualdade racial no Brasil: 120 anos após a abolição. Brasília (DF): Instituto de Pesquisa Econômica Aplicada, 2008.

LEAL, M.C. et al. Desigualdades raciais, sociodemográficas e na assistência ao pré-natal e ao parto, 1999- 2001. Revista de Saúde Pública, São Paulo, v. 39, p. 100-107, 2005.

LOPES, F. Experiências desiguais ao nascer, viver, adoecer e morrer: tópicos em saúde da população negra no Brasil. In: BRASIL. Fundação Nacional de Saúde (FUNASA). Saúde da população negra no Brasil: contribuições para a equidade. Brasília (DF), 2005. 
MARIMÓN, T. N.; MARTINÉZ, C. E. La cooperación técnica OPS/OMS y el aporte de Cuba en la erradicación de la polio en Angola. Revista Cubana de Higiene y Epidemiología, Havana, v. 47, n. 1, 2009.

MOLINA, J. et al. O Programa Mais Médicos e as Redes de Atenção à Saúde no Brasil. Divulgação em Saúde para Debate, Rio de Janeiro, n. 52, p. 190-201, 2014.

MONJE VARGAS, J. A. Salud de exportación: economía política del conocimiento, cooperación internacional y modelos alternativos de desarrollo desde la salud pública cubana. Buenos Aires: Consejo Latinoamericano de Ciencias Sociales, 2014.

OBSERVATÓRIO DE ANÁLISE POLÍTICA EM SAÚDE. Boletim Projeto Análise de Políticas de Saúde no Brasil (2013-2017). Salvador, ano 2017. Disponível em:

<http://www.analisepoliticaemsaude.org/oaps/boletim/edicao/9/ Acesso em: 28 maio 2018.

OLIVEIRA, S.K.M. et al. Saúde em comunidade rural quilombola: relato de experiência sob o prisma dos atributos da atenção primária à saúde. Motricidade, Portugal, v. 8, n. supl. 2, p. 83-88, 2012.

ORGANIZAÇÃO MUNDIAL DA SAÚDE. Conferência Internacional sobre Cuidados Primários de Saúde, 1978, Alma-Ata, URSS. Cuidados primários de saúde: relatório da Conferência. Brasília (DF): UNICEF, 1979.

ORGANIZAÇÃO PANAMERICANA DE SAÚDE (OPAS). Implementação do Programa "Mais Médicos" em Curitiba: experiências inovadoras e lições aprendidas. Brasília (DF), 2015.

PAIM, J. S. Atenção Primária à Saúde: uma receita para todas as estações? Saúde em Debate, Rio de Janeiro, v. 36, n. 94, p. 343-347, jul./set. 2012.

PEREIRA, L. L.; PACHECO, L. O desafio do Programa Mais Médicos para o provimento e a garantia da atenção integral à saúde em áreas rurais na região amazônica, Brasil. Interface, Botucatu, v. 21, supl.1, p. 1181-92, 2017.

SANTOS, F. P. et al. A regulação na saúde suplementar: uma análise dos principais resultados alcançados. Ciência \& Saúde Coletiva, Rio de Janeiro, v. 13, n. 5, p. 1463-1475, 2008.

SANTOS, S. M. et al. Desigualdades raciais na mortalidade de mulheres adultas no Recife, 2001 a 2003. Saúde e Sociedade, São Paulo, v. 16, n. 2, p. 87-102, 2007.

TEIXEIRA, C. F.; SOLLA, J. P. Modelo de atenção à saúde: promoção, vigilância e saúde da família. Salvador: EDUFBA, 2006.

TORALES, A. P. B. Qualidade de vida e autoestima de comunidades quilombolas no Estado de Sergipe. 2013. Tese (Doutorado em Saúde e Ambiente)-Programa de PósGraduação da Universidade Tiradentes, Aracaju, 2013.

TRIBUNAL DE CONTAS DA UNIÃO. Auditoria operacional: Programa Mais Médicos e

Argum., Vitória, v. 10, n. 2, p. 203-219, maio/ago. 2018. 
Projeto Mais Médicos para o Brasil; avaliação da eficácia do programa. TC no 005·391/2014-8. 2014 .

VIEIRA, F. S.; BENEVIDES, R. P. S. O direito à saúde no Brasil em tempos de crise econômica, ajuste fiscal e reforma implícita do Estado. Revista de Estudos e Pesquisas sobre as Américas, Brasília (DF), v. 10, n. 3, 2016.

VOLOCHKO, A.; BATISTA, L. E. Saúde nos quilombos. São Paulo: Instituto de Saúde, GTAE - SESSP, 2009.

Lucélia Luiz PEREIRA Trabalhou na concepção e no delineamento do estudo. Analisou e interpretou os dados e redigiu o artigo.

Doutora em Ciências da Saúde pela Universidade de Brasília (UnB). Docente no Departamento de Serviço Social da UnB. Líder do Núcleo de Análise e Avaliação de Políticas Públicas (NAAPP). Realiza pesquisas nas áreas de Avaliação e Monitoramento de Políticas Sociais, Saúde, Saúde quilombola, Gênero e Raça.

Leonor Maria Pacheco dos SANTOS Trabalhou na interpretação dos dados e na revisão crítica do texto. Aprovou a versão final a ser publicada.

Pós-doutorado em Epidemiologia Materno Infantil, London School of Hygiene and Tropical Medicine (1992); Pós-graduação em Ciência dos Alimentos e Nutrição, Gent Universiteit, Belgium (1982); Doutorado (PhD) em Patologia, University of Tennessee Center for the Health Sciences, USA (1976). Docente no Departamento de Saúde Coletiva da UnB. Tem experiência em pesquisa nas áreas de Avaliação de Políticas de Saúde e Políticas Sociais, Gestão de Ciência e Tecnologia em Saúde, Segurança Alimentar, Nutrição Social, Epidemiologia, Hipovitaminose A e Anemia. 